\title{
PROPERTIES OF FRESH AND HARDENED GEOPOLYMER-BASED GROUTS
}

\author{
JIAN ZHANG, SHUCAI LI, "ZHAOFENG LI, QINGSONG ZHANG, HENGTIAN LI, JUNQI DU, YANHAI QI \\ Geotechnical and Structural Engineering Research Center, Shandong University, \\ Jinan, Shandong, 250061, China \\ "E-mail: lizf@sdu.edu.cn
}

Submitted November 17, 2018; accepted February 15, 2019

\begin{abstract}
Keywords: Fly ash, Ground granulated blast-furnace slag, Fresh-state properties, Compressive strength, Microstructure
A geopolymer blended with fly ash (FA) and ground granulated blast-furnace slag (GGBS) was designed to investigate the properties of geopolymer $(G P)$ - based grouting materials from different aspects. The workability, i.e. flowability, bleeding capacity, setting time and change of viscosity with time, as well as the compressive strength and microstructure of the GP-based grouts were investigated. The ratios of GGBS to FA and the concentration of sodium hydroxide were $0.2-1.0$ and $0.5-4.0 \mathrm{M}$, respectively. The results show that GGBS enhances the flowability, while FA and sodium hydroxide enhance the stability of fresh grouts. The setting time reduces as the ratios of GGBS to FA and sodium hydroxide concentration increase. Sodium hydroxide concentration has a greater effect on the change of viscosity with time compared to the ratios of GGBS to FA. FA and sodium hydroxide reduce the compressive strength of hardened grouts, while GGBS improves their compressive strength. By adjusting the ratios of GGBS to FA and the concentration of sodium hydroxide, the setting time of GP-based grouts could be tailored from 0.5 to $5.5 \mathrm{~h}$, the compressive strength after 28 days was up to $7.48 \mathrm{MPa}$, and the bleeding capacity is less than $2.5 \%$. The optimum GGBS to FA ratio and sodium hydroxide concentration is 0.8 and $2.0 \mathrm{M}$, respectively, which can meet the performance requirements for grouting reinforcements in grouting engineering.
\end{abstract}

\section{INTRODUCTION}

Grouting is a rock and soil stabilization technique that is widely adopted in the treatment of underground engineering disasters [1]. Cement-based grouts are currently the most widely used grouting types. However, the cement industry accounts for approximately $7 \%$ of total carbon dioxide emission per year [2-3]. For this reason, substitutes of cement-based grouts need to be sought.

Geopolymers are materials competitive with Portland cement that reuse industrial solid wastes of aluminosilicate composition in combination with an alkaline activator. They possess high mechanical strength, short setting time and durability [4-5]. What is more, they are of low cost, exhibit negligible carbon dioxide emission during synthesis and thus have a much lower impact on global warming [6]. In consideration of these advantages, geopolymers are considered as potential alternative materials which can be applied in many fields like grouting engineering despite their higher brittleness and fragility [7].

Fly ash is widely used to prepare geopolymers due to its suitable aluminosilicate composition [8]. Many works reported that fly-ash-based geopolymers show an improved compressive strength with ground granulated blast-furnace slag [9-11]. The most widely used alkaline activators for the preparation of geopolymers are hydroxides and silicates of sodium and potassium [12]. Sodium-based activators are usually better than potassium-based activators, because most minerals are more readily dissolved in sodium hydroxide than in potassium hydroxide. What is more, considering the durability of the final hardened body, sodium hydroxide has a better acid-resistance than alkaline silicates [13]. Moreover, sodium hydroxide is cheaper than alkaline silicates and potassium hydroxide, which makes it more attractive in the field of geopolymers.

The majority of studies in the literature is focused on the synthesis and characterization of geopolymers blended with fly ash and blast-furnace slag. Puertas et al. [8] concluded that the ratio of fly ash to slag and the alkali activator concentration are the most significant parameters. De Silva et al. [14] identified that the concentration of $\mathrm{Si}^{4+}$ and $\mathrm{Al}^{3+}$ ions determined the properties of the geopolymer. Chindaprasirt et al. [15-16] investigated the effect of fineness of high calcium fly ash on the properties of fly-ash-based geopolymers. 
Deb et al. [17] concluded that blended $20 \%$ ground granulated blast furnace slag in activated fly ash can yield geopolymers with excellent mechanical properties. Cihangir et al. [18] investigated the effect of slag content, alkali type and concentration on the properties of alkaliactivated slag. Junaid et al. [19] analyzed the effect of the alkaline liquid/fly ash ratio and the water/binder ratio on the properties of fly-ash-based geopolymers.

Fly-ash- and slag-based geopolymers are considered as promising binder materials due to their environmental benefits, as they are by-products from industries and can reduce the demand for Portland cement. The present work focuses on the synthesis and characterization of geopolymers prepared from fly ash and slag. While previous works by other authors have focused on alkali concentration, slag content, dissolution mechanisms and mechanical properties, the present work is mostly about concrete and mortar. Nevertheless, high flowability and stability of grouts are crucial to grouting reinforcement engineering. In order to determine whether geopolymers satisfy the workability and mechanical property require-ments for grouting engineering, it is essential to investigate their basic properties under high water/ solid ratio. Therefore, the overall aim of this work is to study the flowability, bleeding capacity, setting time, viscosity change with time, mechanical properties and microstructure in order to evaluate the performance of geopolymer-based grouting materials. With respect to grouting engineering applications, the most widely used water/binder (W/B) ratio of 1.0 was selected. The ratios of fly ash to ground granulated blast-furnace slag are $0.2,0.4,0.6,0.8$ and 1.0. The concentrations of sodium hydroxide are $0.5,1.0,2.0,3.0$ and 4.0 M. The specimens were cured for $3,7,14$ and 28 days for mechanical property tests. The optimum ratio of ground granulated blast furnace slag to fly ash and concentration of sodium hydroxide are determined and discussed.

\section{EXPERIMENTAL}

\section{Materials and methodology \\ Raw materials characterization}

Fly ash (FA) was supplied from Xinfa plant (Shandong, China) and ground granulated blast-furnace slag (GGBS) was bought from Luxin plant (Shandong, China). The chemical composition of these raw materials was analyzed by X-ray fluorescence (XRF) analysis (Table 1). Sodium hydroxide flakes with $96 \%$ purity (Tianjin Dengke Chemical Reagent Co. Ltd., Tianjin, China) was used as the alkaline activator. The sodium hydroxide solutions were used after cooling down to room temperature.

The amounts of $\mathrm{Al}_{2} \mathrm{O}_{3}+\mathrm{SiO}_{2}+\mathrm{Fe}_{2} \mathrm{O}_{3}$ and $\mathrm{CaO}$ in the FA sample were $92.6 \%$ and $2.87 \%$, respectively, which indicates that the FA is a class-F type according to ASTM C618-08a [20]. The major components of GGBS are oxides of calcium $(\mathrm{CaO})$, silicon $\left(\mathrm{SiO}_{2}\right)$ and aluminum $\left(\mathrm{Al}_{2} \mathrm{O}_{3}\right)$. The X-ray diffraction (XRD) patterns (Figure 1) shows that FA contains quartz, mullite, corundum, hematite, and calcium oxide, while GGBS is found to be a glassy phase with aluminosilicate compounds. The grain size distributions of FA and GGBS have been determined by laser diffraction (Figure 2).

Table 1. Chemical composition of raw materials.

\begin{tabular}{lcccccccc}
\hline Components (\%) & $\mathrm{SiO}_{2}$ & $\mathrm{Al}_{2} \mathrm{O}_{3}$ & $\mathrm{CaO}$ & $\mathrm{Fe}_{2} \mathrm{O}_{3}$ & $\mathrm{~K}_{2} \mathrm{O}$ & $\mathrm{MgO}$ & $\mathrm{Na}_{2} \mathrm{O}$ & $\mathrm{LOI}$ \\
\hline FA & 59.53 & 29.4 & 2.87 & 3.67 & 1.15 & 0.43 & 0.2 & 2.75 \\
GGBS & 20.5 & 12.1 & 57.2 & 0.55 & 0.58 & 5.05 & 0.36 & 3.66 \\
\hline
\end{tabular}

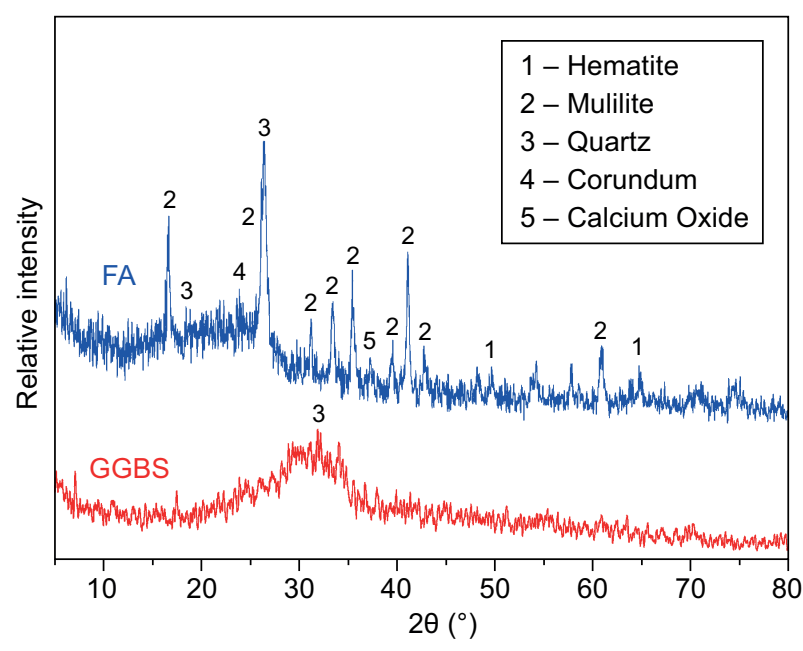

Figure 1. XRD patterns for FA and GGBS.

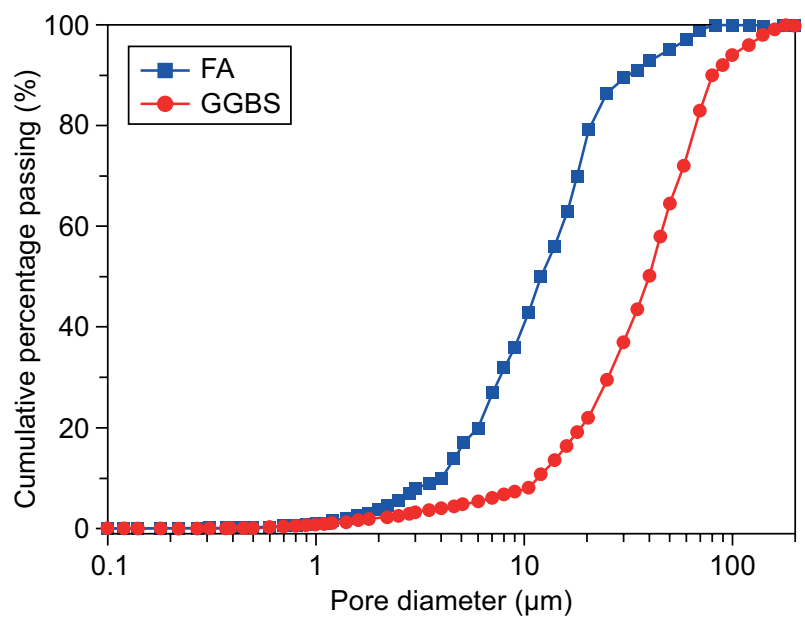

Figure 2. Particle size distributions of FA and GGBS. 


\section{Experimental design}

A total of five different GGBS-FA mixtures were prepared by varying the ratios of GGBS to FA. The GGBS-FA mixes are denoted as $\mathrm{S} 1, \mathrm{~S} 2, \mathrm{~S} 3, \mathrm{~S} 4$ and $\mathrm{S} 5$ for the ratios of $0.2,0.4,0.6,0.8$ and 1.0 , respectively. Sodium hydroxide solutions with different concentrations of $0.5,1.0,2.0,3.0$ and $4.0 \mathrm{M}$ were designed to investigate the effect of alkaline activator concentration on the grouts properties. The mixture proportions are shown in Table 2. Initially, a specific amount of sodium hydroxide was added to the required water, taking into account the mass of sodium hydroxide for calculating the amount of required water. The fresh paste was stirred at a speed of $240 \mathrm{rpm}$ for $5 \mathrm{~min}$. A water-to-solid (W/S) ratio of 1.0 has been selected for this study, because it is widely used in grouting engineering. All the measurements were conducted at a temperature of $21 \pm 1{ }^{\circ} \mathrm{C}$.

Table 2. Mixture proportions of the GP-based grouts.

\begin{tabular}{ccc}
\hline Number & $\begin{array}{c}\text { Ratios of GGBS } \\
\text { to FA }\end{array}$ & $\begin{array}{c}\mathrm{NaOH} \text { concentration } \\
\text { (M) }\end{array}$ \\
\hline S1 & 0.2 & $0.5-4$ \\
S2 & 0.4 & $0.5-4$ \\
S3 & 0.6 & $0.5-4$ \\
S4 & 0.8 & $0.5-4$ \\
S5 & 1.0 & $0.5-4$ \\
\hline
\end{tabular}

\section{Mini-slump tests}

Mini-slump tests were performed on a smooth glass with a test mold [21] to characterize the fluidity of FA-based geopolymer. The mold dimensions were: height $60 \mathrm{~mm}$, bottom diameter $36 \mathrm{~mm}$ and top diameter $60 \mathrm{~mm}$.

\section{Bleeding capacity tests}

Bleeding capacity tests was conducted to show the stability of GP-based grout. After fresh slurry preparation, 11 of the slurry was placed in a graduated cylinder with a diameter of $63 \mathrm{~mm}$, and the volume of sediment was recorded until initial coagulation of the slurry [22].

\section{Setting time tests}

The initial and final setting time was recorded as the time when the penetration height of the Vicat needle is $25 \mathrm{~mm}$ and less than $1 \mathrm{~mm}$, respectively, according to the ASTM Standard C191 [23].

\section{Viscosity measurements}

The viscosity of the grout is crucial to grouting engineering. The viscosity test with time was conducted using SV - 10 and SV - 100 sine wave vibration viscometers (Aiande Co., Ltd., Japan). The viscosity ranges were $0.3-10000 \mathrm{mPa} \cdot \mathrm{s}$ and $1-100 \mathrm{~Pa} \cdot \mathrm{s}$, respectively.

\section{Compressive strength}

The fresh GP-based grouts were rapidly poured into cylindrical PVC molds, the specimens were demolded after $24 \mathrm{~h}$ and cured in water immediately after demolding. The unconfined compressive strength test was conducted according to the relevant ASTM Standard C942-15. The specimens were tested three times and the average of the strength was recorded as the unconfined compressive strength for each mix proportion. Compressive strength was tested after $3,7,14$ and 28 days.

\section{Microstructural characterization}

The microstructure of FA-based geopolymer was analyzed by XRD, IR, and SEM. For this characterization of geopolymers, the fragments of specimens after the compressive strength test were collected and soaked in ethanol to quenched the geopolymerization reaction. The morphology of GP-based geopolymer was studied by SEM using a ZEISS-55 scanning electron microscope at an accelerating voltage of $20 \mathrm{kV}$ and spot size of 6.0. The XRD analysis was conducted on a Rigaku Miniflex 600 with $\mathrm{Cu} \mathrm{K} \alpha$ radiation at a scanning rate of $10^{\circ} \mathrm{min}^{-1}$ from $10^{\circ}$ to $80^{\circ}(2 \theta)$. The IR analysis was conducted by a Vertex 70 FTIR spectrophotometer (Bruker, Germany) in the spectral range from 400 to $4000 \mathrm{~cm}^{-1}$. Mercury intrusion porosimetry (MIP) was performed to study the pore structure of the hardened grout. The MIP measurements were conducted with a Quantachrome Poremaster-60 with a maximum intrusion pressure of $410 \mathrm{MPa}$. The contact angle and surface tension of mercury were assumed to be $140^{\circ}$ and $480 \mathrm{mN} \cdot \mathrm{m}^{-1}$, respectively.

\section{RESULTS}

Mini-slump of fresh grouts

Results of mini-slump tests, which characterize the flowability of GP-based grouts, are shown in Figure 3.

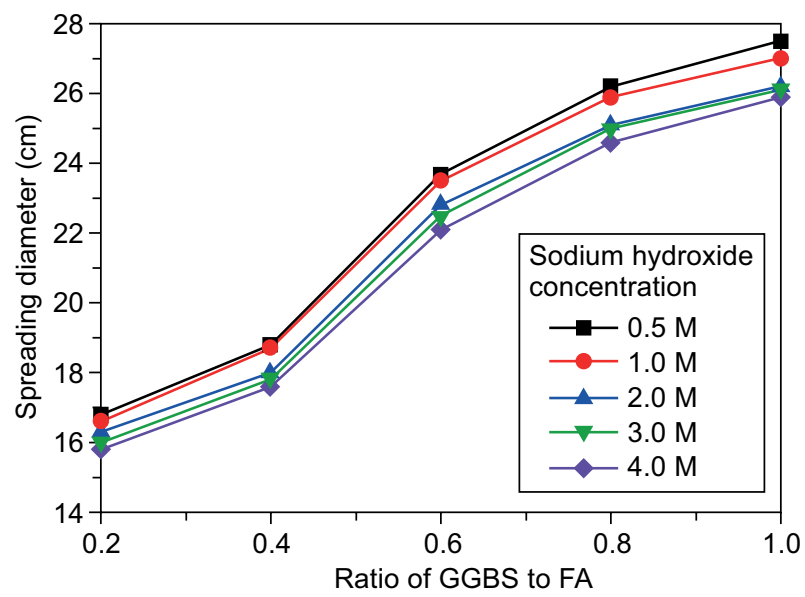

Figure 3. Mini-slump diameters (spreading diameters) of fresh GP-based grouts. 
The mini-slump diameters (spreading diameters) of GP-based grouts increased with increasing ratio of GGBS to FA (S1 to S5) and decreased with increasing concentration of sodium hydroxide $(0.5$ to $4 \mathrm{M})$. When the ratios of GGBS to FA were $0.2,0.4,0.6,0.8$ and 1.0 , the mini-slump diameters of fresh grouts $(0.5-4 \mathrm{M}$ sodium hydroxide) were 15.8 - 16.6, 17.6 - 18.7, 22.1 - 23.5, $23.5-24.6$ and $25.9-27 \mathrm{~cm}$, respectively. As illustrated in Figure 3, FA and sodium hydroxide decreased the minislump diameters of suspensions, FA has a positive effect on the spreading ability when its admixture percentage is below $40 \%$ due to its "ball effects" and "filling effect" [24]. However, as the admixture percentage is above $40 \%$, FA has a negative effect on the spreading of the grout, because, apart from glassy phase, there are also about $40 \%$ of crystalline compounds and unburned carbon in FA. With increasing FA content, the specific surface area and water requirement are increased, and the fluidity is reduced. With increasing concentration of sodium hydroxide, the leaching time of $\mathrm{Si}^{4+}$ and $\mathrm{Al}^{3+}$ decreased and the leached amount increased, which is inversely proportional to the spreading ability, though the effect is weak. GGBS played a positive role in increasing the spreading ability due to its "filling effect" and "micro-aggregate effect". Considering engineering applications, the ratio of GGBS to FA can range from 0.6 to 1.0 .

\section{Bleeding capacity of fresh grouts}

The results of bleeding capacity tests are displayed in Figure 4. According to ASTM C940 the GP-based grout is "stable", if its bleeding capacity is $<5 \%$ after initial coagulation of the slurry [25].

In Figure 4 it is shown that the bleeding capacity increased with the increasing ratio of GGBS to FA. At the same time the bleeding capacity of suspensions decreased as the sodium hydroxide concentration increased. When the ratios of GGBS to FA were 0.2, 0.4,

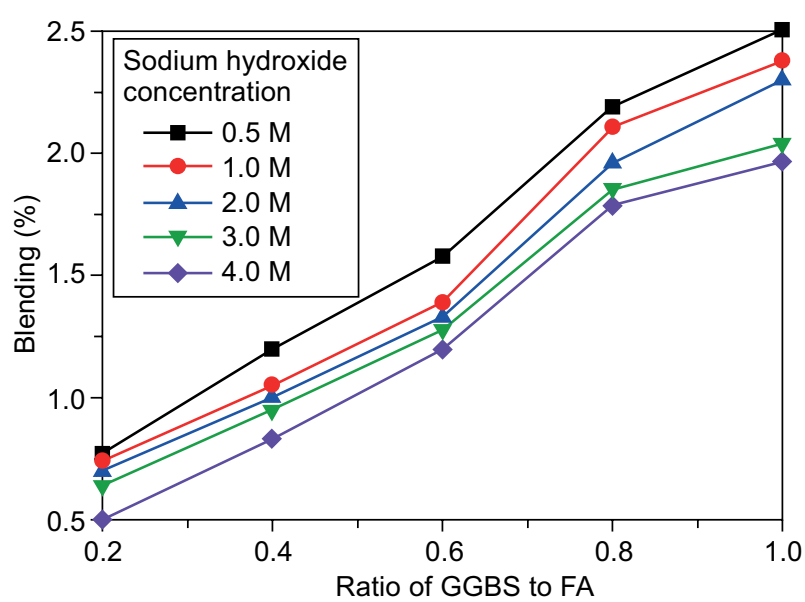

Figure 4. Bleeding capacity (\%) of fresh GP-based grouts.
$0.6,0.8$ and 1.0 , the bleeding capacity of grouts $(0.5$ - $4 \mathrm{M}$ sodium hydroxide) were $0.5-0.74,0.83-1.16$, $1.2-1.49,1.65-2$ and $1.97-2.38 \%$, respectively.

FA can reduce the bleeding capacity of GP-based grout, which is related to the surface area of FA, as the specific surface area of FA is larger, and more water is needed to cover the surface with a water film, thus reducing free moisture and reducing the bleeding capacity. By contrast, GGBS played a negative role in decreasing the bleeding capacity due to its low water demand and "filling effect". As presented in Figure 4, the sodium hydroxide concentration played a positive role on the bleeding capacity, because as the sodium hydroxide concentration increased, the leached amount of $\mathrm{Si}^{4+}$ and $\mathrm{Al}^{3+}$ increased and more water was needed to form geopolymer networks. Stable GP-based grouts are recommended in practical grouting engineering, because excessive bleeding capacity leads to a decrease of grout fluidity, resulting in the blockage of pipes and the normal construction process [26], thus the ratios of GGBS to FA were suggested to not exceed 0.8 .

\section{Setting time of fresh grouts}

Figure 5 illustrates the setting time of the GP-based grouts with different ratios of GGBS to FA and sodium hydroxide concentration.

Figure 5 demonstrates that the initial and final setting time of GP-based grouts shortened as the ratios of GGBS to FA increased. This is probably because GGBS contains a substantially higher amount of amorphous aluminosilicate phase than FA as evidenced by the diffuse peak found from XRD analysis (Figure 1), and the degree of $\mathrm{Si}^{4+}$ and $\mathrm{Al}^{3+}$ leaching is higher in the case of GGBS compared to FA. In addition, GGBS contains a high content of $\mathrm{CaO}$, and $\mathrm{Ca}^{2+}$ exhibits stronger electrostatic attraction and charge neutralization compared to $\mathrm{Na}^{+}$. The geopolymerization process is accelerated under the condition of a larger amount of $\mathrm{Ca}^{2+}$. At the same time, however, a large amount of calcium silicate gel was generated, thus shortening the setting time.

As seen in Figure 5, the initial and final setting times of GP-based grouts have been significantly shortened with the increment of sodium hydroxide concentration (since the setting times for specimens with $0.5 \mathrm{M}$ sodium hydroxide were too long, they were not recorded in the experiment). During the leaching reaction, the alkalinity of the sodium hydroxide solution leads to the release of $\mathrm{Si}^{4+}, \mathrm{Al}^{3+}$ and $\mathrm{Ca}^{2+}$ from GGBS and $\mathrm{FA}$, which then diffuse out of the geopolymerization products that form rapidly around the unreacted particles. Alkaline conditions accelerate the activation process, while the presence of hydroxide enhances slag dissolution and also improves the solubility of aluminosilicate [27].

It needs to be pointed out that GP-based grout with different sodium hydroxide concentration will be suitable for different grouting engineering applications. 


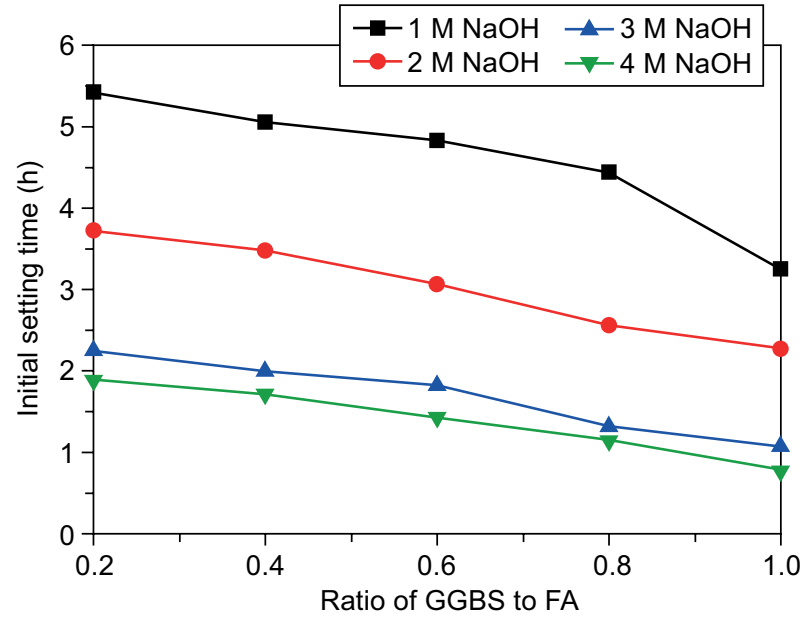

a)

Figure 5. Setting times of the fresh GP-based grouts.

\section{Change of viscosity with time}

The viscosity of GP-based grouts with different ratios of GGBS to FA and sodium hydroxide concentration were measured as a function of time.

As shown in Figure 6, the viscosity change of the fresh-state GP-based grouts has a low viscosity stage and a solidifying stage. In the stage of low viscosity, the leaching reaction took place, and the viscosity stayed almost the same. As the leaching reaction proceeds, a large number of $\mathrm{Si}^{4+}$ and $\mathrm{Al}^{3+}$ ions were leached out and the polymerization process and hydration reaction began, the viscosity increased rapidly, and then the solidifying stage appeared.

In Figure 6a we can see that the curves of S1, S2 and S3 have a similar trend of viscosity change. As the ratios of GGBS to FA increased to 0.8 , the slope of curves turned down, because the GGBS content increased and FA content decreased as the ratios of GGBS to FA

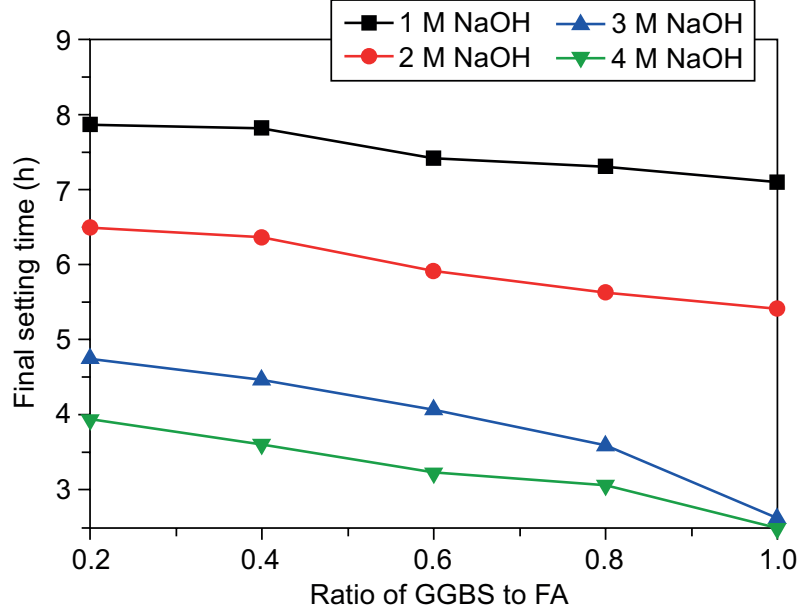

b)

increased, and the "filling effect" and "micro-aggregate effect" of GGBS played a positive role in the fresh-state GP-based grout.

The effect of sodium hydroxide concentration on the viscosity change with time is shown in Figure 6b. In the solidifying stage, the viscosity value and its growth rate are lower. This can be attributed to the slow leaching reaction and the low amounts of $\mathrm{Si}^{4+}$ and $\mathrm{Al}^{3+}$ under conditions of lower sodium hydroxide concentration. As the concentration increases, the low viscosity stage is shorter and then the viscosity increases rapidly to the initial coagulation, followed by rapid thickening. At this time, GP-based grout presents a mixture of solid and liquid, with flow and diffusion. GP-based grout loses its fluidity after the final coagulation, and the viscosity stays almost the same. This phenomenon can be attributed to the rapid leaching reaction, while the concentration of sodium hydroxide is high.

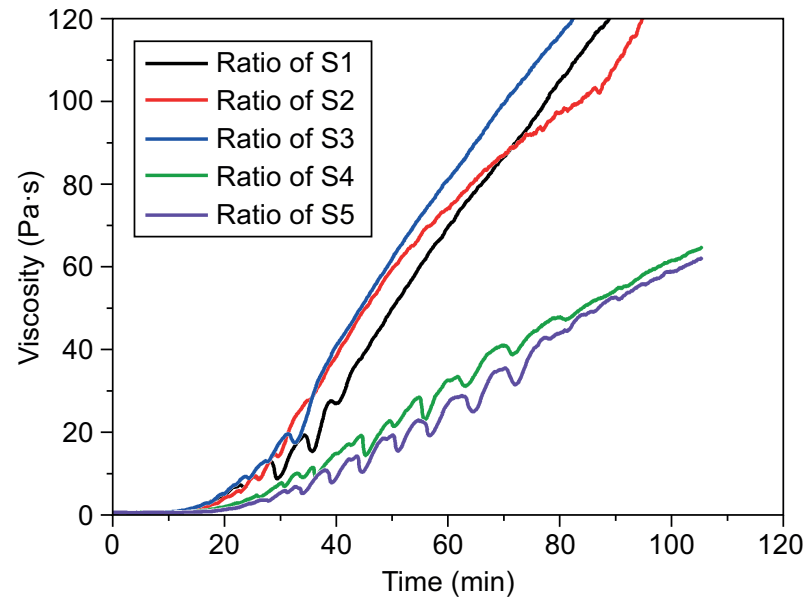

a)

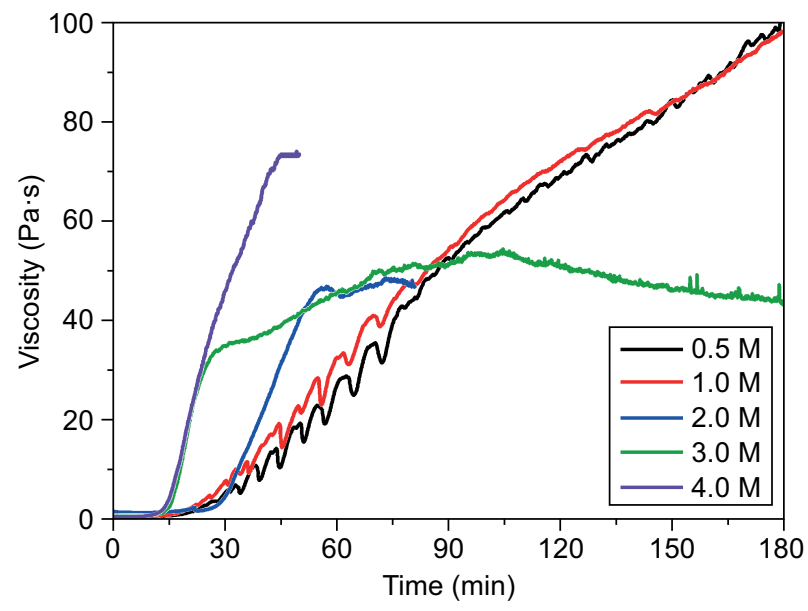

b)

Figure 6. Change of viscosity of fresh GP-grouts with time for (a) different ratios of GGBS to FA with $1 \mathrm{M} \mathrm{NaOH}$, (b) different sodium hydroxide concentration (GGBS to FA ratio of 0.8 ). 
Compressive strength

Figure 7 shows the 3, 7, 14, 28 days compressive strength of hardened GP-based grouts with different ratios of GGBS to FA and sodium hydroxide concentration.

As shown in Figure 7, compressive strength increased with increasing GGBS to FA ratio (for the same concentration of sodium hydroxide). The phenomenon can be attributed to the high reactivity of soluble aluminosilicate components under alkaline conditions, the increased GGBS to FA ratio causing an increase content of $\mathrm{Si}^{4+}$ and $\mathrm{Al}^{3+}$ in the slurry. The silicon and aluminum content accelerates the geopolymerization process, which is beneficial for compressive strength. GGBS contains mostly reactive aluminosilicates, and the activity of GGBS is much higher than that of fly ash. Moreover, the percentage of calcium oxide in the GGBS promoted the hydration process. Thus, the compressive strength is directly correlated with the ratio of GGBS to FA.

SEM observations were performed at the age of 28 days, and the effects of the ratios of GGBS to FA and sodium hydroxide concentration were studied. The results are shown in Figures 8 and 9. The SEM images are indicative of the presence of geopolymeric products.

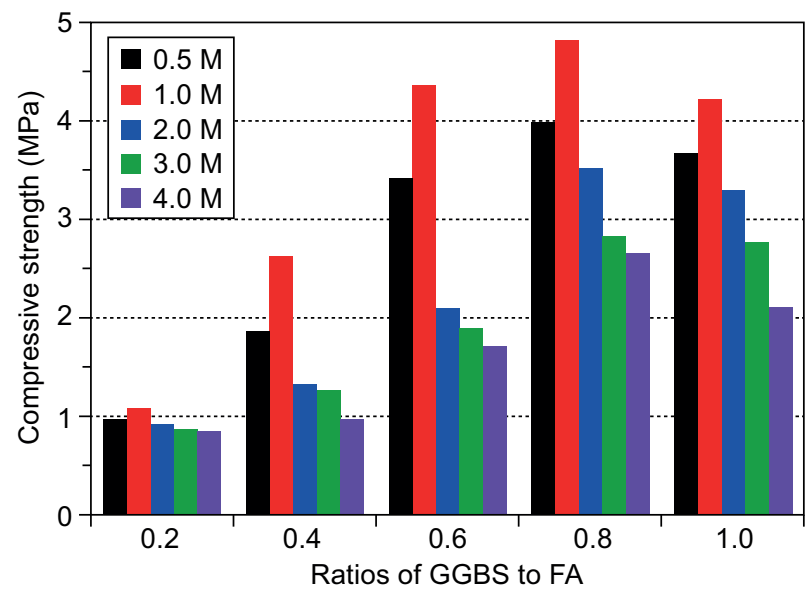

a) 3 days

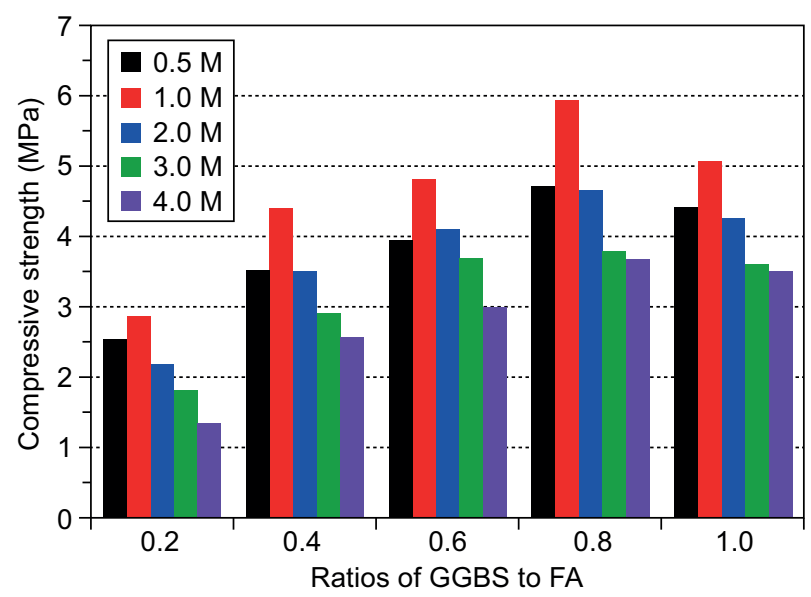

c) 14 days
As illustrated in Figure 8, the polymerization degree is lower for a low ratio (S1) of GGBS to FA as compared to the high ratio (S5). Unreacted FA can be found from $\mathrm{S} 1$, which indicates that FA particles have a slow rate of dissolution of aluminosilicates in sodium hydroxide solution when the ratio of GGBS to FA is low. For a high ratio of GGBS to FA, a large quantity of aluminosilicate hydration products and $\mathrm{C}-\mathrm{S}-\mathrm{H}$ are seen, due to the high calcium content in the slag, the microstructure is more compact and the amorphous $\mathrm{C}-\mathrm{S}-\mathrm{H}$ and geopolymer gel strengthen the final product, similar to findings reported previously [28-29]. Also the compressive strength is higher for high ratios of GGBS to FA than for low ratios, which is consistent with the conclusion of Figure 7.

Figure 7 also illustrates the compressive strength with different concentrations of sodium hydroxide solution. It can be observed that the alkali concentration has a significant effect on the compressive strength. The compressive strength increased when the sodium hydroxide concentration increased from $0.5 \mathrm{M}$ to $1.0 \mathrm{M}$, but then decreased when the concentration increased from 1.0 $\mathrm{M}$ to $4.0 \mathrm{M}$. Sodium hydroxide acts as activator in the leaching reaction, and $\mathrm{Na}^{+}$is important for the charge balance in the paste [15]. At a lower sodium hydroxide

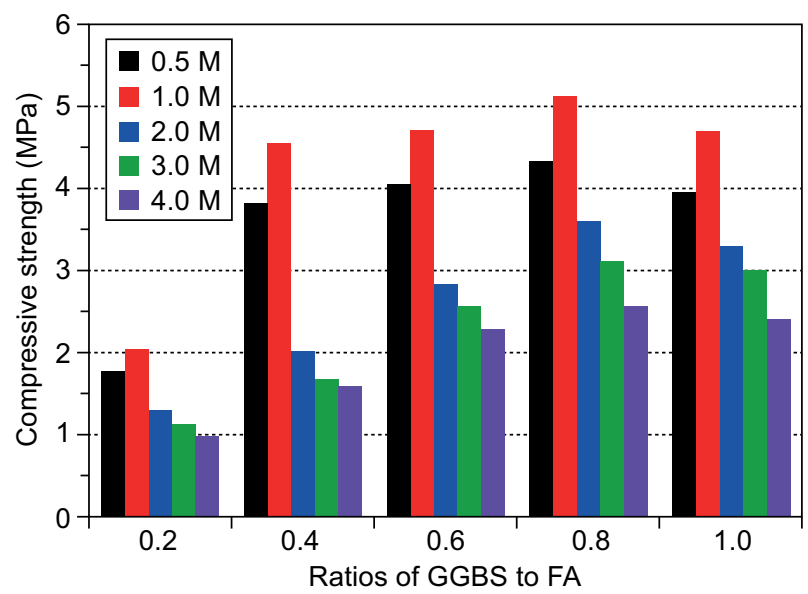

b) 7 days

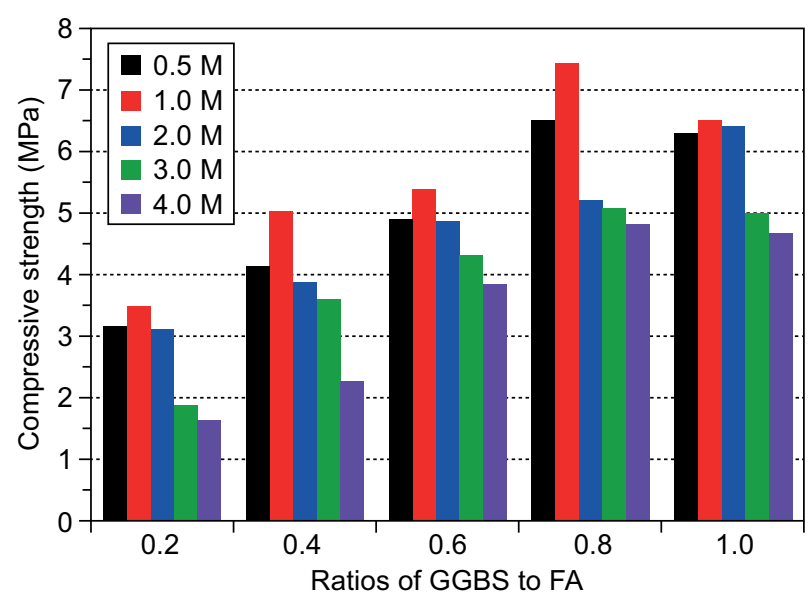

d) 28 days

Figure 7. Compressive strength of geopolymer-based grouts with different curing time: a) 3 d, b) 7 d, c) 14 d, d) 28 d. 


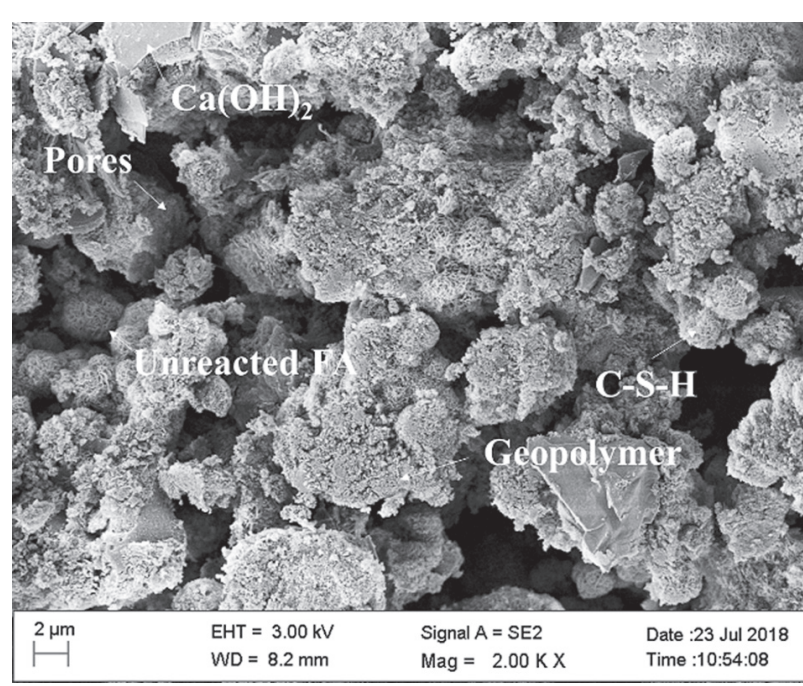

a) $\mathrm{S} 1-1.0 \mathrm{M}$

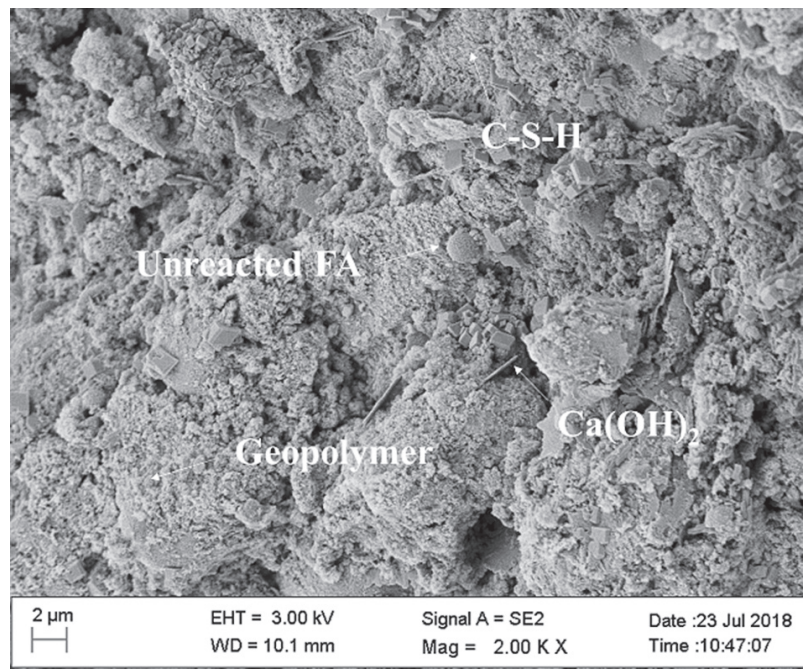

c) $\mathrm{S} 3-1.0 \mathrm{M}$

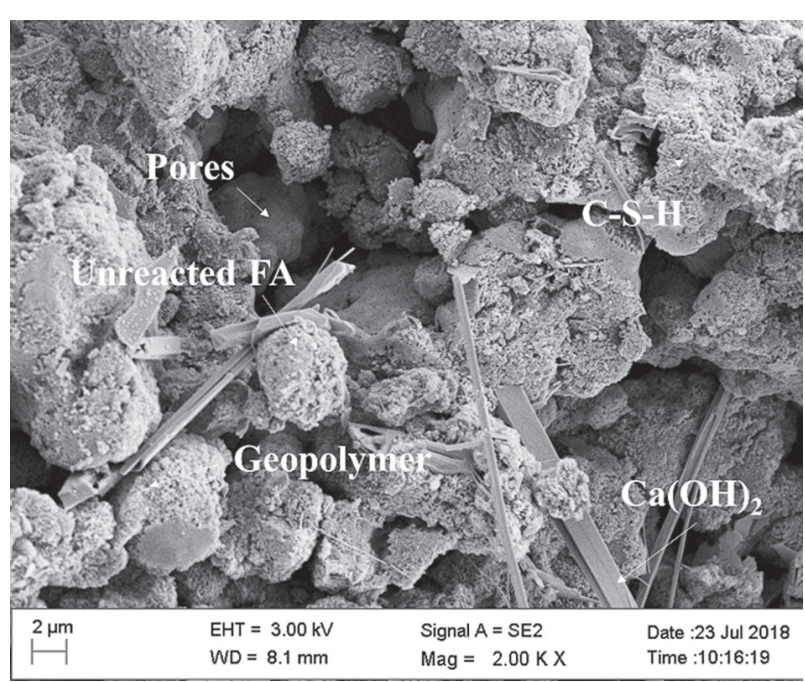

b) $\mathrm{S} 2-1.0 \mathrm{M}$

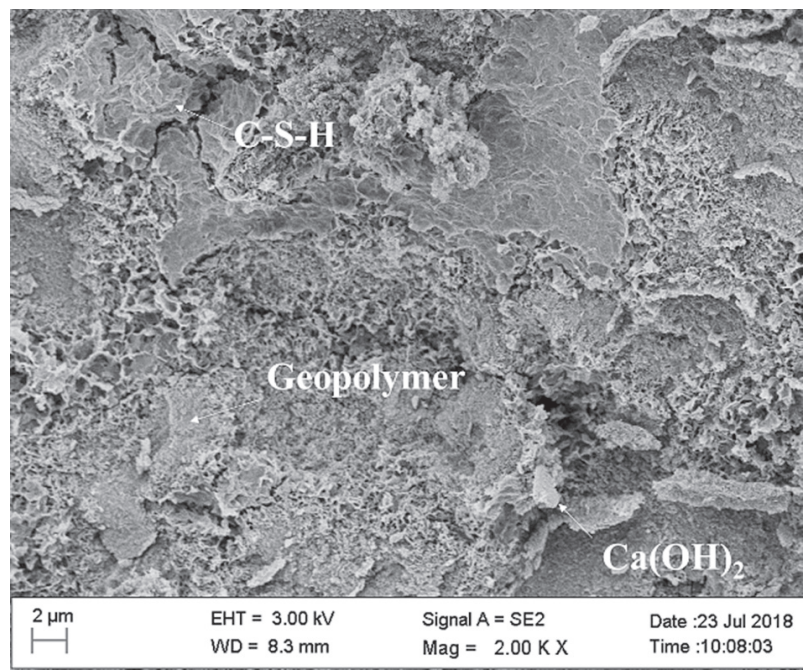

d) $\mathrm{S} 4-1.0 \mathrm{M}$

Figure 8. SEM images of GP-based grouts with different GGBS to FA ratios.

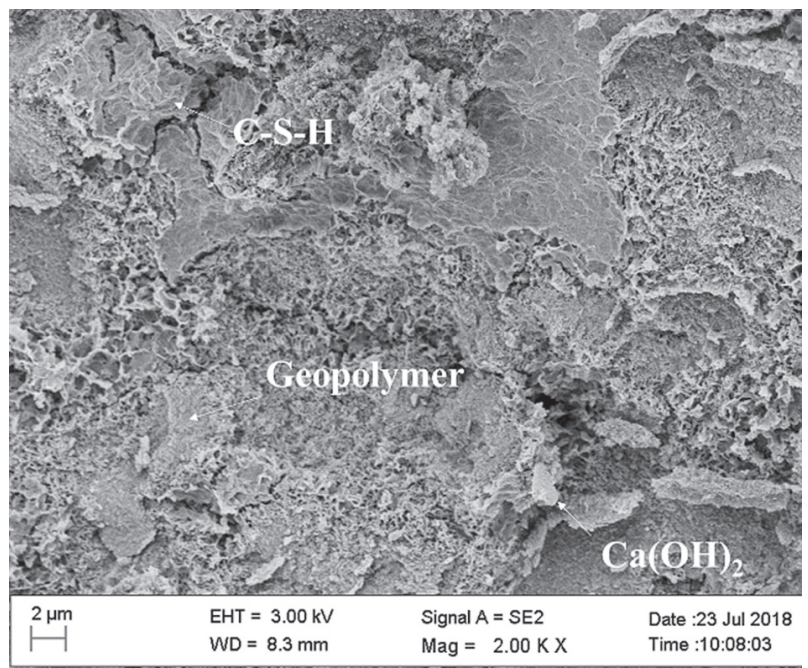

a) $\mathrm{S} 4-1.0 \mathrm{M}$

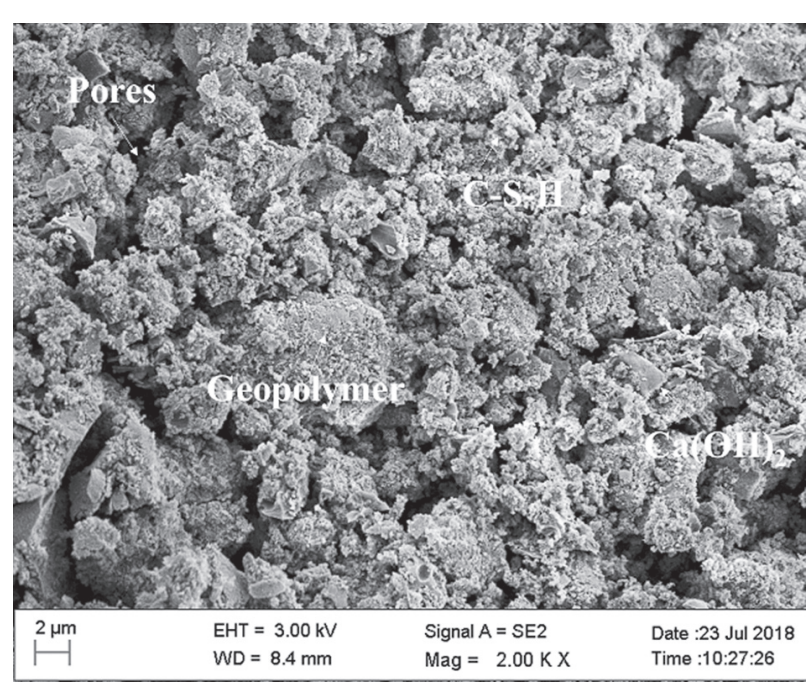

b) $\mathrm{S} 4-2.0 \mathrm{M}$

Figure 9. SEM images of GP-based grouts prepared with different $\mathrm{NaOH}$ concentration. (Continue on next page) 


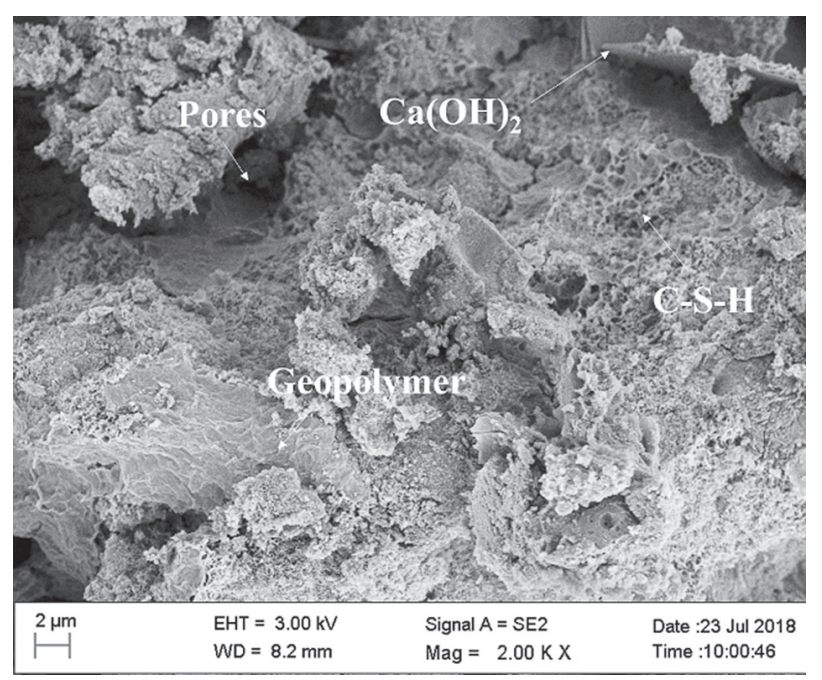

c) S4-3.0 M

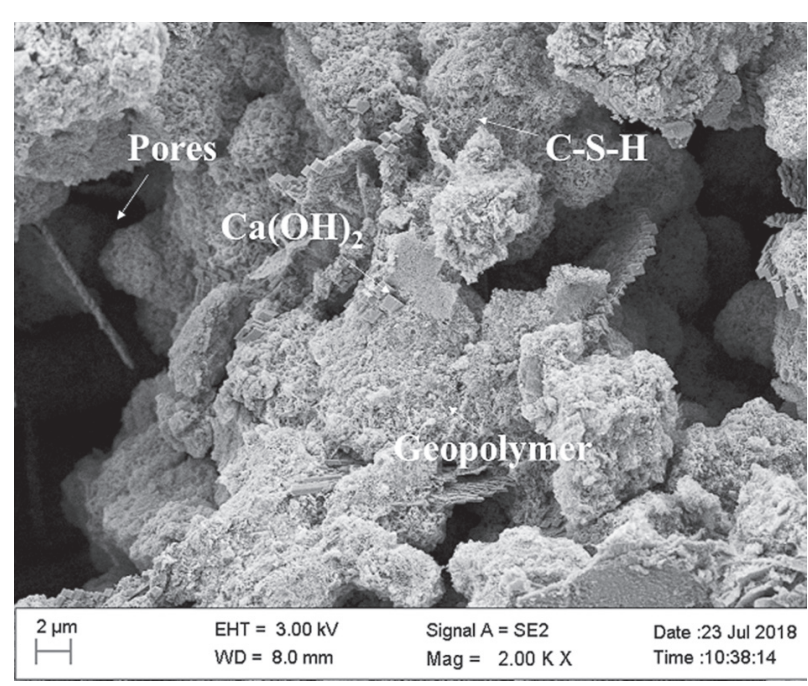

d) $\mathrm{S} 4-4.0 \mathrm{M}$

Figure 9. SEM images of GP-based grouts prepared with different $\mathrm{NaOH}$ concentration.

concentration, less $\mathrm{Si}^{4+}$ and $\mathrm{Al}^{3+}$ dissolved, resulting in a weak geopolymeric network. A proper compressive strength is observed at $1.0 \mathrm{M}$ sodium hydroxide concentration for all GP-grouts. The leached $\mathrm{Si}^{4+}$ and $\mathrm{Al}^{3+}$ concentrations are the maxima which enhance the geopolycondensation process at $1.0 \mathrm{M}$ sodium hydroxide. It indicated that equilibrium is maintained between dissolved $\mathrm{Si}^{4+}$ and $\mathrm{Al}^{3+}$ and $\mathrm{Na}^{+}$at $1.0 \mathrm{M}$ sodium hydroxide. Moreover, at higher concentration beyond 8.0 M, the amount of leached aluminosilicates stays almost constant, and the concentration of free sodium hydroxide increased. This results in a lower $\mathrm{Si} / \mathrm{Na}$ ratio in the hardened grout, which has a negative effect on the geopolymerization process and results in a reduction of strength [30].

GP-based grouts prepared with different sodium hydroxide concentration are shown in Figure 9. FA particles cannot be found in the specimens with higher sodium hydroxide concentration, because the leaching time becomes shorter and the amount of $\mathrm{Si}^{4+}$ and $\mathrm{Al}^{3+}$

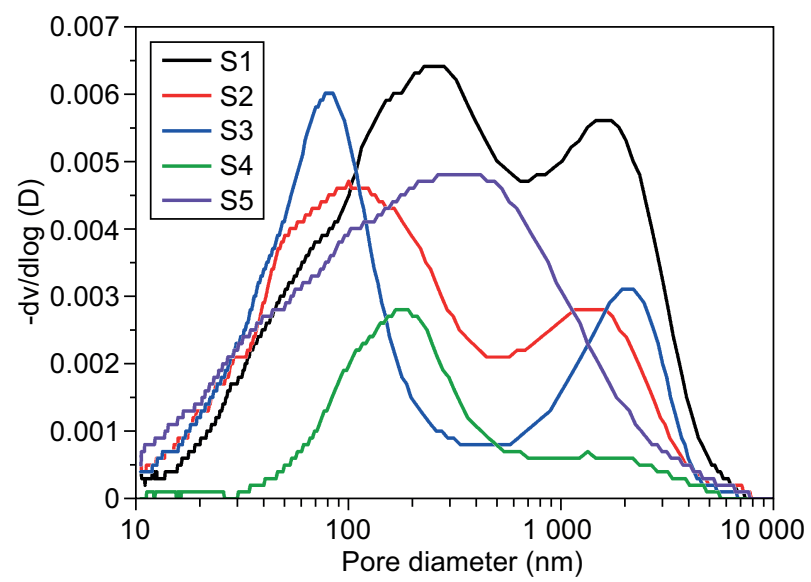

a) is increased with a higher amount of sodium hydroxide. What is more, a high amount of pores can be found in the specimens with lower sodium hydroxide as compared to the other. This can be attributed to the shorter setting time, which also explains the lower compressive strength of specimens with higher concentration of sodium hydroxide, see Figure 7.

Furthermore, the pore size distribution of the specimens with different ratios of GGBS to FA and sodium hydroxide concentrations were analyzed by MIP (Figure 10).

Figure 10a shows the pore size distribution of GP-grouts with different ratios of GGBS to FA. The curve of S1 presents dominant pore diameters larger than $200 \mathrm{~nm}$. The modes of this distribution are around 300 and $2000 \mathrm{~nm}$ (diameters). This indicates that the hardened grout has a large number of pores resulting from unreacted FA. The curve of S4 shows that the dominant pore diameter is $180 \mathrm{~nm}$, and the maximum of the distribution is in the range $70-300 \mathrm{~nm}$. This is

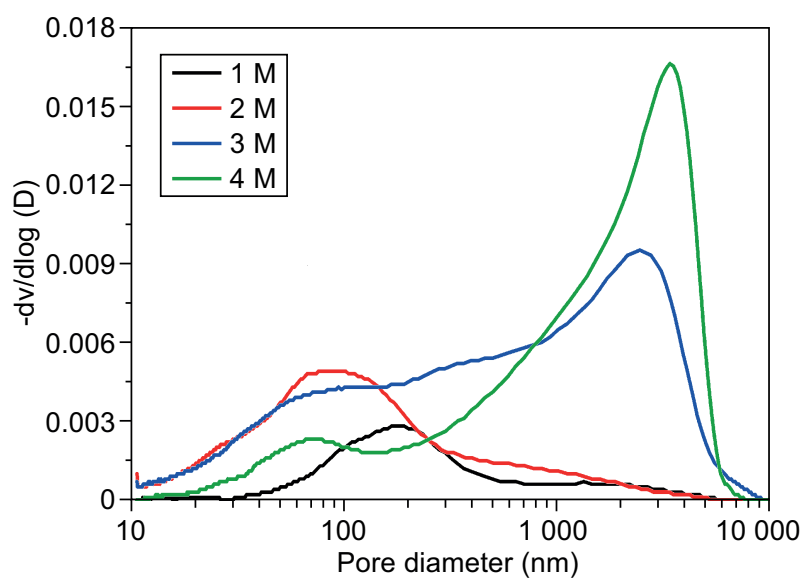

b)

Figure 10. Pore size distribution of GP-based grouts with: a) different ratios of GGBS to FA, b) different NaOH concentration. 
because the large capillary pores (around $100-1000 \mathrm{~nm}$ ) are space-filled by the aluminosilicate gels, and thus the hardened grout shows only one mode when a denser pore structure developed [31].

Figure 10b shows the pore size distribution of GPgrouts with different sodium hydroxide concentration. The curves for sodium hydroxide concentrations of $3 \mathrm{M}$ and $4 \mathrm{M}$ show that the dominant diameters are about 3000 and $4000 \mathrm{~nm}$, respectively. This can be attributed to the short setting time and the high water/solid ratio. For sodium hydroxide concentrations of $1 \mathrm{M}$ and $2 \mathrm{M}$, the dominant diameters go down to 90 and $180 \mathrm{~nm}$ with the longer setting time.

It is interesting to note that the effect of alkali activator concentration on the mechanical properties of GP-based grout is different for grouting material as compared to concrete and mortar. Most researchers used activator solutions with molarity ranges between 8.0 and 14.0 M [30-34], but for grouting materials, as the W/S ratio is much bigger than for concrete and mortar, the content alkali activator, related to the solids, remains the same as the concentration decreased. On the basis of this fact, we may conclude that the concentration of alkali activator and the amount of alkali activator related to the solid both affect the mechanical properties.

\section{CONCLUSIONS}

According to the requirements for grouting materials in grouting reinforcement engineering, the setting time, flowability, viscosity change with time, bleeding capacity, compressive strength and microstructures of GP-based grouts blended with FA, GGBS and sodium hydroxide were investigated. The main conclusions may be summarized as follows:

- The ratios of GGBS to FA and the concentration of sodium hydroxide significantly affect the fresh-state properties of GP-based grouts. GGBS can improve the flowability of fresh grouts, while FA and sodium hydroxide reduce the bleeding capacity of fresh grout. The effects of sodium hydroxide on the flowability and bleeding capacity are smaller than those of FA and GGBS, but, compared to the ratios of GGBS to FA, the sodium hydroxide concentration has a greater effect on the change of the viscosity with time.

- The compressive strength of GP-based grouts increases with the increasing ratios of GGBS to FA, as long as this ratio is below 0.8 , but decreases for ratios ranging from 0.8 to 1.0 . Higher sodium hydroxide concentration has a negative effect on the compressive strength, when the amount of sodium hydroxide is enough for the leaching reaction.

- According to the microstructures of hardened GP-based grouts, the degree of hydration and the amount of hydration products of the GP-based grouts are relatively low, and unreacted FA can be found in the specimens with low ratios of GGBS to FA, while a dense hardened grout is obtained as these ratios get higher. The pore diameters between hydration products are large and the microstructures of the hardened grouts are loose, when the concentration of sodium hydroxide is high. The pore size distribution of GP-based grout with different sodium hydroxide concentration further explained the effect of sodium hydroxide concentration on the compressive strength.

- The performance of the geopolymer-based cementitious grout slurry with 50 - $60 \%$ FA, 40 - $50 \%$ GGBS and $1.0-2.0 \mathrm{M}$ sodium hydroxide studied in this paper satisfies the properties of grouting engineering.

\section{Acknowledgment}

This study was financially supported by the Major Project of Chinese National Programs for Fundamental Research and Development (Project No. 2017YFC0703100), the Major Basic Project of Shandong Provincial Natural Science Foundation of China (Project Nos. ZR2017ZC0734), the Young Scientists Funds of National Natural Science Foundation of China (Grants Nos. 51709158), the China Postdoctoral Science Foundation Funded Project (No. 2018M632676) and the Fundamental Research Funds of Shandong University (Grants No. 2016GN027).

\section{REFERENCES}

1. Li S., Liu R., Zhang Q., Zhang X. (2016): Protection against water or mud inrush in tunnels by grouting: A review. Journal of Rock Mechanics and Geotechnical Engineering, 8, 753-766. doi: 10.1016/j.jrmge.2016.05.002

2. Schneider M., Romer M., Tschudin M., Bolio H. (2011): Sustainable cement production-present and future. Cement and Concrete Research, 41, 642-650. doi: 10.1016/j. cemconres.2011.03.019

3. Benhelal E., Zahedi G., Shamsaei E., Bahadori A. (2013): Global strategies and potential to curb $\mathrm{CO}_{2}$ emissions in cement industry. Journal of Cleaner Production, 51, 142-161. doi: 10.1016/j.jclepro2012.10.049

4. Davidovits J. (1989): Geopolymers and geopolymeric new materials. Journal of Thermal Analysis, 35 (2) 429-441. doi: 10.1007/BF01904446

5. Davidovits J. (2008). Geopolymer Chemistry and Applications. Geopolymer Institute, Saint-Quentin.

6. Panias D., Giannopoulou I.P., Perraki T. (2007): Effect of synthesis parameters on the mechanical properties of fly ash-based geopolymers, Colloids and Surfaces A: Physicochemical and Engineering Aspects, 301 (1) 246-254. doi:10.1016/j.colsurfa.2006.12.064

7. Zhang S., Gong K., Lu J. (2004): Novel modification method for inorganic geopolymer by using water soluble organic polymers. Material Letters, 58, 1292-6. doi: 10.1016/ j. matlet.2003.07.051. 
8. Puertas F., Martinez-Ramiirez S., Alonso S., Vazquez T. (2000): Alkali-activated fly ash/slag cements: strength behaviour and hydration products. Cement and Concrete Research, 30 (10) 1625-1632. doi: 10.1016/S0008-8846 (00)00298-2

9. Davidovits J. (2002): 30 years of successes and failures in geopolymer applications. Market trends and potential breakthroughs. in: Proceedings of Geopolymer 2002 Conference, Geopolymer Institute, Melbourne (Australia). pp. 1-16.

10. Samantasinghar S., Singh S.P. (2018): Effect of synthesis parameters on compressive strength of fly ash-slag blended geopolymer. Construction and Building Materials, 170, 225-234. doi: 10.1016/j.conbuildmat.2018.03.026

11. Sun Z., Lin X., Anya Vollpracht A. (2018): Pervious concrete made of alkali activated slag and geopolymers. Construction and Building Materials, 20, 797-803. doi:10.1016/j.conbuildmat.2018.09.067

12. Xu H., Van Deventer J.S.J. (2000): The geopolymerisation of alumino-silicate minerals. Int. J. Miner. Process. International Journal of Mineral Processing, 59 (3), 247-266. doi: 10.1016/S0301-7516(99)00074-5.

13. Bakharev T. (2005): Resistance of geopolymer materials to acid attack. Cement and Concrete Research, 35 (4), 658-670. doi: 10.1016/j.cemconres.2004.06.005

14. De Silva P., Sagoe-Crenstil K., Sirivivatnanon V. (2007): Kinetics of geopolymerization: role of $\mathrm{Al}_{2} \mathrm{O}_{3}$ and $\mathrm{SiO}_{2}$. Cement and Concrete Research, 37 (4), 512-518. doi: 10.1016/j.cemconres.2007.01.003

15. Rattanasak U., Chindaprasirt P. (2009): Influence of $\mathrm{NaOH}$ solution on the synthesis of fly ash geopolymer. Minerals Engineering, 22 (12), 1073-1078. doi: 10.1016/j.mineng. 2009.03.022

16. Chindaprasirt P., Chareerat T., Hatanaka S., Cao T. (2011): High-strength geopolymer using fine high-calcium fly ash. Journal of Materials in Civil Engineering, 23 (3), 264-270. doi: 10.1061/(ASCE)MT.1943-5533.0000161

17. Deb P.S., Nath P., Sarker P.K. (2014): The effects of ground granulated blast-furnace slag blending with fly ash and activator content on the workability and strength properties of geopolymer concrete cured at ambient temperature. Materials \& Design, 62, 32-39. doi: 10.1016/j.matdes.2014. 05.001

18. Cihangir F., Ercikdi B., Kesimal A., Deveci H., Erdemir F. (2015): Paste backfill of high sulphide mill tailings using alkali-activated blast furnace slag: effect of activator nature, concentration and slag properties. Minerals Engineering, 83, 117-127. doi: 10.1016/j.mineng.2015.08.022

19. Junaid M.T., Kayali O., Khennane A., Black J. (2015): A mix design procedure for low calcium alkali activated fly ash-based concretes. Construction and Building Materials, 79, 301-310. doi: 10.1016/j.conbuildmat.2015.01.048

20. ASTM C618-05 (2005): Standard Specification for Coal Fly Ash and Raw or Calcined Natural Pozzolan for Use in Concrete. West Conshohocken, PA.
21. Kantro D.L. (1980): Influence of water reducing admixtures on properties of cement paste a miniature slump test, Cement, Concrete and Aggregates, 2, 95-102. doi: 10.1520/ CCA10190J

22. Pantazopoulos I.A., Markou I.N., Christodoulou D.N., Droudakis A.I., Atmatzidis D.K., Antiohos S.K., Chaniotaki E. (2012): Development of microfine cement grouts by pulverizing ordinary cements. Cement and Concrete Composites, 34 (5), 593-603. doi: 10.1016/j.cemconcomp. 2012.01.009

23. ASTM C191-13 (2013): Standard Test Methods for Time of Setting of Hydraulic Cement by Vicat Needle. West Conshohocken, PA.

24. Cristelo N., Soares E., Rosa I., Miranda T., Oliveira D. V., Silva R. A., Chaves A. (2013): Rheological properties of alkaline activated fly ash used in jet grouting applications. Construction and Building Materials, 48, 925-933. doi: 10.1016/j.conbuildmat.2013.07.063

25. Jayasree C., Gettu R. (2008): Experimental study of the flow behavior of superplasticized cement paste, Materials and Structures, 41 (9), 1581-1593. doi: 10.1617/s11527008-9350-5

26. Rosquoe F., Alexis A., Khelidj A., Phelipot A. (2003): Experimental study of cement grout: Rheological behavior and sedimentation. Cement and Concrete Research, 33 (5), 713-722. doi: 10.1016/S0008-8846(02)01036-0

27. Marjanović N., Komljenović M., Baščarević Z., Nikolić V., Petrović R. (2015): Physical-mechanical and microstructural properties of alkali-activated fly ash-blast furnace slag blends. Ceramics International, 41 (1), 1421-1435. doi: 10.1016/j.ceramint.2014.09.075

28. Nagalia G., Park Y., Abolmaali A., Aswath P. (2016): Compressive strength and microstructural properties of fly ash-based geopolymer concrete. Journal of Materials in Civil Engineering, 28 (12), 04016144. doi: 10.1061/(asce) mt.1943-5533.0001656

29. Zhang Z., Wang H., Provis J.L. (2012): Quantitative study of the reactivity of fly ash in geopolymerization by FTIR. Journal of Sustainable Cement-Based Materials, 1 (4), 154-166. doi: 10.1080/21650373.2012.752620

30. Dimas D., Giannopoulou I.P., Panias D. (2009): Utilization of alumina red mud for synthesis of inorganic polymeric materials. Mineral processing \& Extractive metallurgy review, 30 (3), 211-239. doi: 10.1080/08827500802498199

31. Sun Z., Lin X., Vollpracht A. (2018): Pervious concrete made of alkali activated slag and geopolymers. Construction and Building Materials, 20, 797-803. doi:10.1016/j.conbuildmat.2018.09.067

32. Yang T., Yao X., Zhan Z. (2014): Geopolymer prepared with high-magnesium nickel slag: Characterization of properties and microstructure. Construction and Building Materials, 59, 188-194. doi: 10.1016/j.conbuildmat.2014.01.038 